\title{
Correction to: Feasibility and Validity of Printing 3D Heart Models from Rotational Angiography
}

\author{
Manoj Parimi ${ }^{1} \cdot$ John Buelter ${ }^{1} \cdot$ Vignan Thanugundla $^{2} \cdot$ Sri Condoor $^{2} \cdot$ Nadeem Parkar $^{1} \cdot$ Saar Danon ${ }^{1} \cdot$ Wilson King $^{1}$
}

Published online: 2 April 2018

○) Springer Science+Business Media, LLC, part of Springer Nature 2018

\section{Correction to: Pediatric Cardiology https://doi.org/10.1007/s00246-017-1799-y}

The original version of this article unfortunately contained a mistake. The third author's name is incorrectly displayed as Vignan Thangundla instead of Vignan Thanugundla and the affiliation of the authors Manoj Parimi, John Buelter, Nadeem Parkar, Saar Danon, Wilson King have to be corrected as Saint Louis University School of Medicine, 1402 South Grand Blvd, St. Louis, MO, 63104 USA. The original article has been corrected.

The original article can be found online at https://doi.org/10.1007/ s00246-017-1799-y.

Wilson King

kingw@slu.edu

1 Saint Louis University School of Medicine, 1402 South Grand Blvd, St. Louis, MO 63104, USA

2 Saint Louis University Parks College of Engineering, St. Louis, USA 